\title{
Numerical simulation of the SASW test
}

\author{
N. Gucunski \\ Department of Civil and Environmental Engineering, Rutgers University, Piscataway, New Jersey 08855-0909, USA
}

\&

\section{R.D. Woods}

Department of Civil Engineering, The University of Michigan, Ann Arbor, Michigan 48109-2125, USA

(Received 6 January 1992; accepted 8 January 1992)

\begin{abstract}
The paper describes numerical simulation of the SASW test. Influences of the test setup and applied filtering criteria on the accuracy of the obtained field dispersion curve for various soil stratification conditions have been examined. The results presented indicate significant variations in the evaluated dispersion in cases of irregular soil profiles if the existing criteria are applied. A new filtering criteria has been proposed.
\end{abstract}

Key words: nondestructive testing, Rayleigh waves, dispersion, layered half-space, numerical methods, SASW method.

\section{INTRODUCTION}

The shear modulus of soil represents an essential parameter in the analysis of dynamically excited structures resting on soil. The most common way of in situ evaluation of the shear modulus is by using seismic methods. The Spectral-Analysis-of-Surface-Waves (SASW) method is a method which can accurately define elastic moduli and layer thicknesses of layered systems, like soils and pavements, with a special advantage that is performed entirely from the surface. The method utilizes dispersion of Rayleigh waves in layered systems, i.e. that Rayleigh waves of different frequencies propagate with different velocities.

The SASW test consists basically of three phases: 1) collection of data in the field; 2) evaluation of the Rayleigh wave dispersion curve; and 3) inversion of the dispersion curve to obtain the shear wave velocity profile. The first two phases are straightforward tasks which have been to a great extent automized. The third phase has two major disadvantages. It is a manual process, greatly dependent on the experience of the user, and in cases of profiles of irregular stratification, i.e. when the shear wave velocity does not increase with depth, an ambiguous task. ${ }^{2,3}$

Soil Dynamics and Earthquake Engineering 0267-7261/92/\$05.00 (C) 1992 Elsevier Science Publishers Ltd.
The goal of the study was to produce adequate numerical modelling of the SASW test and utilize it in simulation of the test in various situations of soil stratification. Special attention was given to the examination of influence of the currently accepted criteria for the test setup on the uniqueness of the obtained shear wave velocity profile.

\section{THE SPECTRAL-ANALYSIS-OF-SURFACE- WAVES METHOD}

A schematic of the current testing configuration is presented in Fig. 1. Surface waves are generated by an impact source, detected by a pair of receivers, and recorded on an appropriate recording device. Wave Form Analyzer is a preferred device because it has built-in spectral functions necessary for instantaneous inspection of the recorded data. The experimental dispersion curve for a single receiver spacing $X$ is defined from the relationships presented in Fig. 2, where $f$ represents frequency in $\mathrm{Hz}$, and $\beta$ the phase difference if a propagating wave between two receivers in degrees obtained from the cross power spectrum of signals is detected by the receivers. The test is repeated for several receiver spacings to cover a desired range of Rayleigh wavelengths. The generally used criteria for the acceptance of the range of wavelengths as a function of the source to 


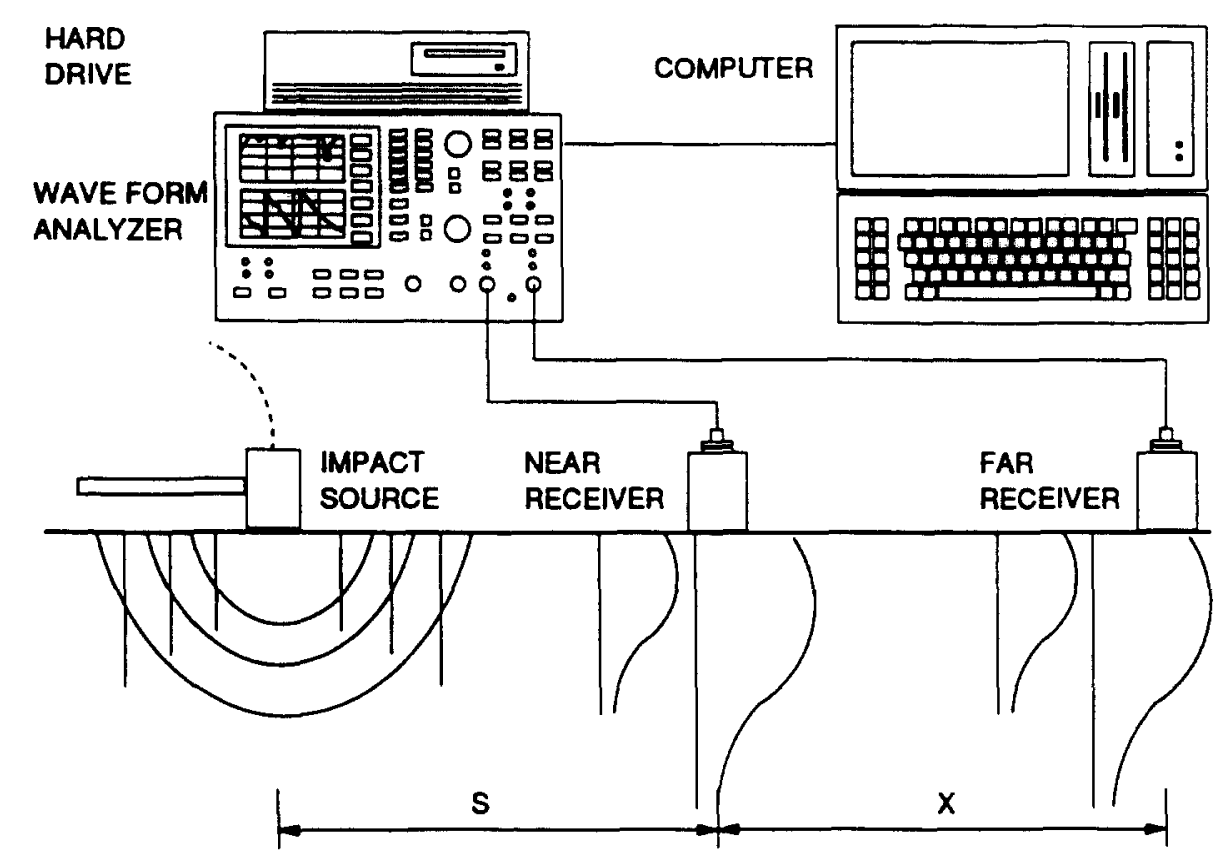

Fig. 1. Schematic of experimental arrangement for SASW test. ${ }^{3}$

near receiver spacing $S$ and the receiver spacing $X$ comes from the experimental study by Heisey et al. ${ }^{5}$ They suggested for an experimental arrangement in which $S$ is equal to $X$, the acceptable wavelengths can be expressed by,

$$
\frac{\lambda_{\text {ph }}}{3}<X<2 \lambda_{\text {ph }}
$$

An experimental study by Sheu et al. ${ }^{15}$ and theoretical studies by Lysmer, ${ }^{10}$ Sanchez-Salinero et al. ${ }^{14}$ Roesset et al. ${ }^{13}$ and Gucunski ${ }^{1}$ propose a different filtering criteria than eqn (1). These alternate criteria suggest that the accepted wavelengths $\lambda_{\text {ph }}$ are in the range $0 \cdot 5-1 \mathrm{~S}$, when the receiver spacing $X$ is in the range $0 \cdot 5-1 \mathrm{~S}$. The test is performed in two directions to cover effects of dipping layers and internal phase shifts due to receivers and instrumentation, as described by Nazarian \& Stokoe."

Dispersion curves for several receiver spacings and two directions are statistically combined to define an average dispersion curve, as described by Nazarian. ${ }^{12}$ This is illustrated in Fig. 3. The average dispersion curve from field data is compared in the inversion process to the theoretically defined dispersion curves for an assumed profile. Once the match between the dispersion curve and the selected path in the field of theoretical curves is established, the assumed profile is accepted as a solution. As described by Gucunski \& Woods ${ }^{3}$ selection of the path in cases of improper stratification represents a

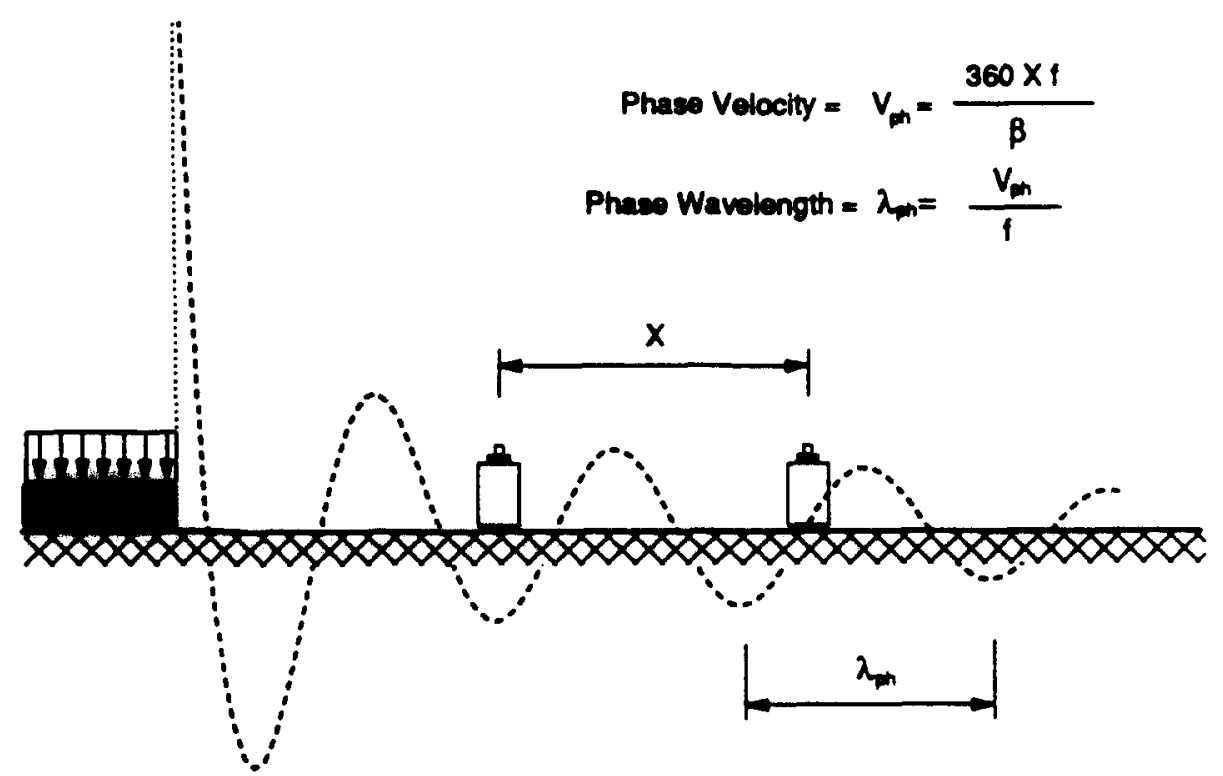

Fig. 2. Evaluation of the phase velocity of a $R$-wave. ${ }^{3}$ 


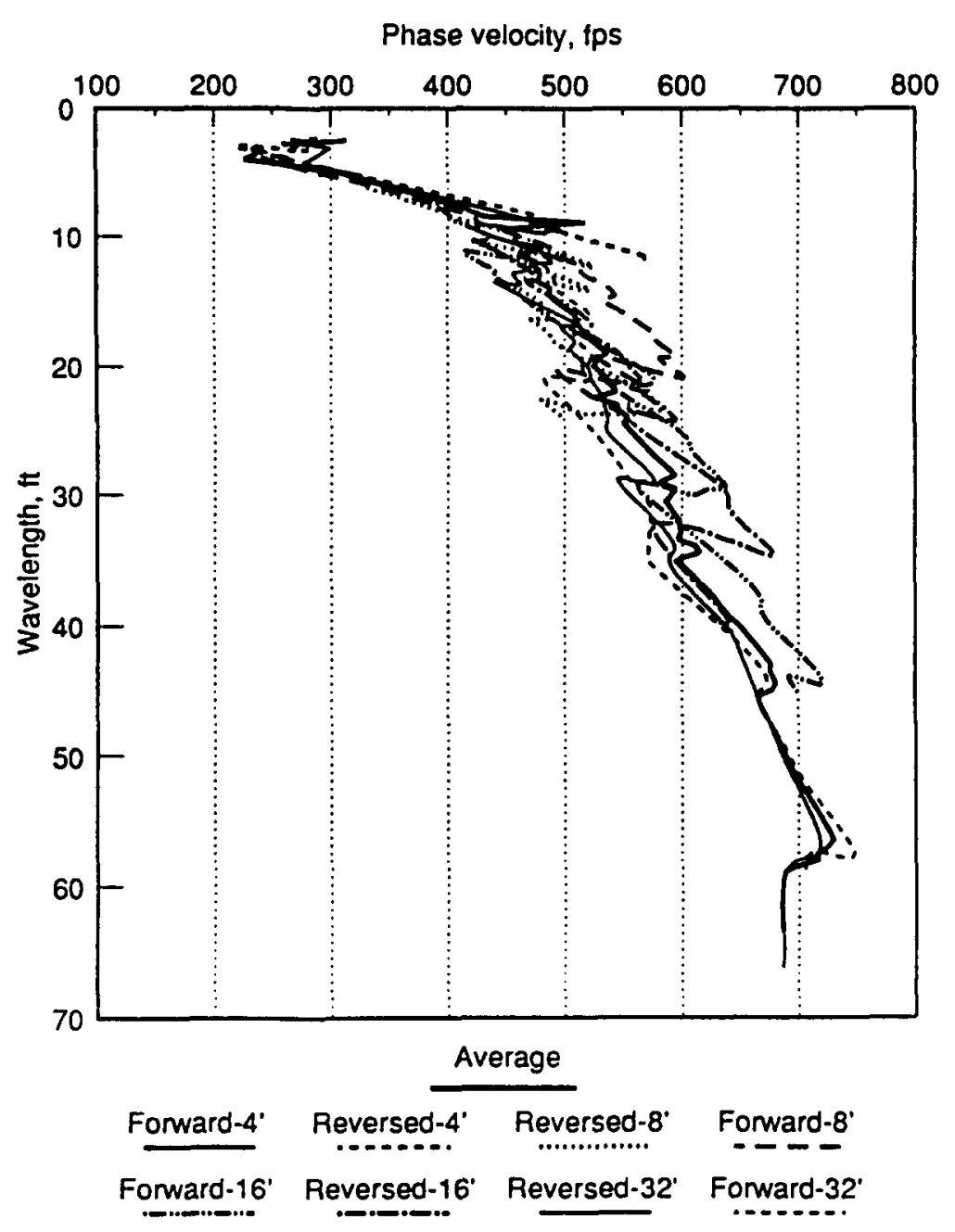

Fig. 3. A typical set of dispersion curves for a soil profile and an average dispersion curve. ${ }^{3}$

major obstacle, and should be dealt with according to the procedures suggested in that paper.

Detailed discussions about the SASW method and instrumentation used in SASW testing can be found in Nazarian," Hiltunen, ${ }^{6}$ Gucunski ${ }^{1}$ and Gucunski \& Woods. ${ }^{4}$

\section{NUMERICAL SIMULATION OF THE SASW TEST}

The SASW test can be described as an axisymmetric problem in which the impact source is represented by a circular loading at the center of the system, while the response of receivers is represented by displacements, velocities or accelerations of the surface at distance $r$ from the source, as shown in Fig. 4. The following sections describe definition of displacements in the spatial domain and energy transmission in the radial direction, due to vertical oscillations of a circular flexible disk at the surface of a layered medium. Rayleigh modes are also defined. The derivations are based on the stiffness matrix approach to the solution of problems of dynamic loads in layered media, as described by Kausel
\& Roesset, ${ }^{8}$ and implemented by $\mathrm{Kausel}^{7}$, Kausel \& Peek, ${ }^{9}$ Wolf \& Obernhuber ${ }^{16}$ and Wolf. ${ }^{17}$

An arbitrary time loading is transformed from the time to the frequency domain by applying Fourier transforms, and from the spatial domain to the frequency-wave number domain by applying Hankel's transforms. For a particular frequency $f$ and wave number $k$, the vertical surface displacement $w_{0}(r)$ in the spatial domain due to uniform vertical loading of radius $R$ and intensity $p_{0}$ can be written as

$$
w_{0}(r)=-p_{0} R \int_{0}^{\infty} J_{1}(k R) J_{0}(k r) w_{0}(k) \mathrm{d} k
$$

in which $J_{0}$ and $J_{1}$ represent Bessel functions of the first kind of the order zero and one, respectively. The term $w_{0}(k)$ represents the vertical surface displacement in the frequency-wave number domain. It is obtained from solution of the system

$$
\mathbf{S}(f, k) \mathbf{u}(k)=\mathbf{p}(k)
$$

in which $\mathbf{S}(f, k)$ represents the stiffness matrix of a layered system, $\mathbf{p}(k)$ the vector of interface loadings, and $\mathbf{u}(k)$ the vector of interface displacements. Vector $\mathbf{p}(k)$ 


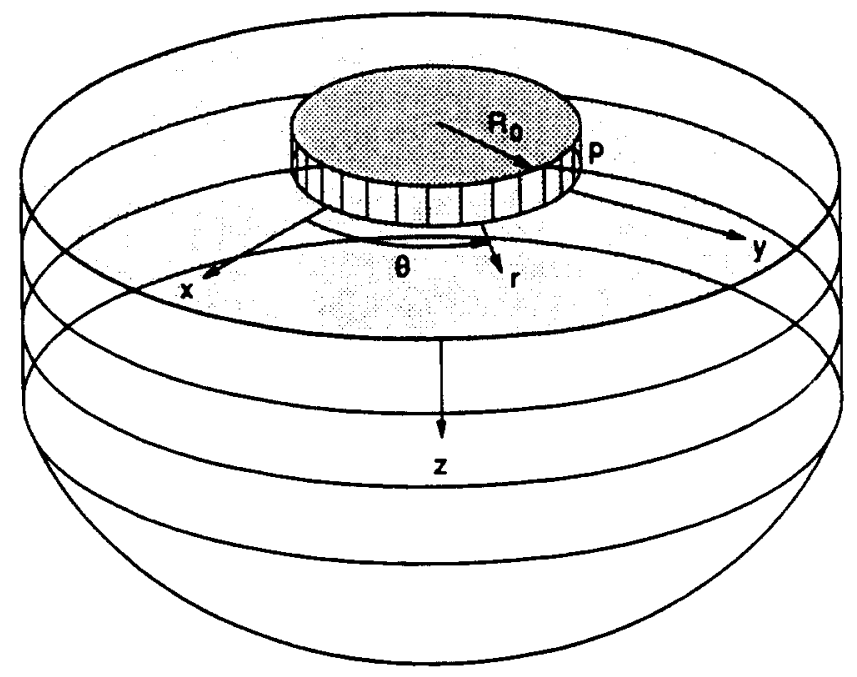

Fig. 4. An axisymmetric model of a soil system with circular loading. ${ }^{3}$

has all components zero, except the unit vertical component at the surface.

Rayleigh modes can be characterized as natural modes of oscillations in axisymmetric systems or as natural modes of wave propagation in plane cases, and they can be determined from a solution of an eigenvalue problem

$$
\mathbf{S}(f, k) \mathbf{u}=\mathbf{0}
$$

in which the eigenvalue, for fixed frequency $f$, represents the phase velocity $V_{\mathrm{ph}}$ of a Rayleigh wave, and is equal to $2 \pi f / k$, while the eigenvector $\mathbf{u}$ represents its shape as function of depth.

The rate of energy transmission $E_{\mathrm{r}}$ represents the amount of energy propagating in the radial direction over the depth $d$ and unit width of a layer and averaged over a period $1 / f$. It is defined as

$$
\begin{aligned}
E_{\mathrm{r}}= & \frac{1}{2} \int_{0}^{d}\left(\operatorname{Re}\left[\sigma_{\mathrm{r}}(z)\right] \operatorname{Re}[\dot{u}(z)]+\operatorname{Im}\left[\sigma_{\mathrm{r}}(z)\right] \operatorname{Im}[\dot{u}(z)]\right. \\
& \left.+\operatorname{Re}\left[\tau_{\mathrm{r} z}(z)\right] \operatorname{Re}[\dot{w}(z)]+\operatorname{Im}\left[\tau_{\mathrm{r} z}(z)\right] \operatorname{Im}[\dot{w}(z)]\right) \mathrm{d} z
\end{aligned}
$$

where $u$ and $w$ represent displacements in the radial and vertical directions, respectively. The goal of this analysis was only to determine the participation of particular layers in overall energy transmission. Therefore, the normalized rate for layer $i, E_{\mathrm{r} n i}$, was introduced which is defined as

$$
E_{\mathrm{r} n i}=\frac{E_{\mathrm{r} i}}{\sum_{j=1}^{n} E_{\mathrm{r} j}}
$$

where $n$ represents the total number of layers including the half-space.

Figure 5 presents vertical surface displacement in the frequency-wave number domain due to vertical oscillations of a circular plate with uniform loading. The variable parameters presented in Fig. 5 include the layer thicknesses $d_{j}$, the slenderness ratio $B_{s}$, representing the ratio of the radius and the thickness of the plate, the mass density of the plate $\rho$, the Poisson's ratio $v$ and the damping ratio $\xi$ of soil. The strong peak displacements represent Rayleigh waves. Modal displacements or displacements in the spatial domain due to Rayleigh waves are calculated based on eqn (3) and on the assumption that the contributing intervals of integration span ranges $\left(I_{n}\right)$ as shown in Fig. 5.

Figure 6 is an example of vertical displacements in the spatial domain due to the same source as in Fig. 5. It would be appropriate at this stage to introduce the definition of the 'simulated' dispersion curve, even though it will be extensively represented in the following parametric study. The 'simulated' dispersion curve represents the dispersion curve evaluated from the displacement curve in the spatial domain, as indicated in Fig. 6 by the wavelength of a propagating wave starting at a distance of one wavelength from the source.

\section{PARAMETRIC STUDY}

\section{(a) Rayleigh wave dispersion}

Four cases of soil stratification, as shown in Fig. 7, have been analyzed and compared in terms of parameters described in the previous section. Also, the SASW test for those four profiles was simulated and dispersion curves obtained according to Heisey's criteria presented in this paper were compared. Case 1 represents a soil profile of regular soil stratification, i.e. when the shear wave velocity increases with depth, while cases 2,3 and 4 represent cases of irregular soil stratification. Case 2 represents a soil system with a softer layer trapped between a harder surface layer and a halfspace. Case 3 is an example of a system with a harder surface layer. Finally, case 4 represents a case of a harder layer trapped between softer layers. Thick soft layers 


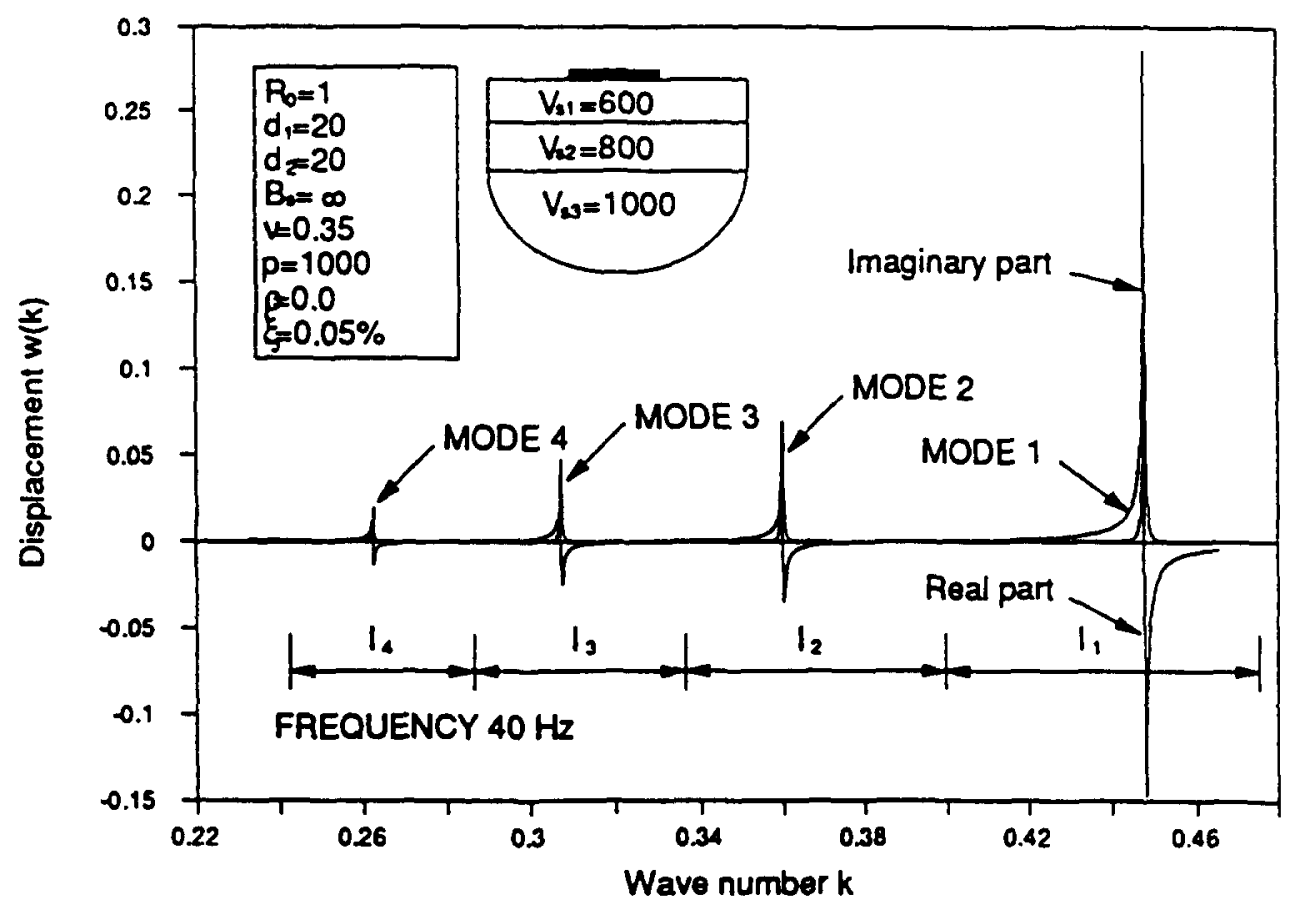

Fig. 5. Vertical displacements in the frequency-wave number domain and intervals of integration for evaluation of modal displacements. ${ }^{1}$

in cases 3 and 4 represent essentially a half-space. The only reason they are underlain by a half-space of a higher shear velocity is to satisfy the condition that Rayleigh waves with pure real velocity in an undamped medium can be obtained only if the half-space has the highest or equal to the highest shear wave velocity of the system.

Figures 8, 9, 10 and 11 present dispersion curves, modal displacements and normalized energy transmission rates for the four cases, respectively. Specifically, the results include the dispersion curves in two formats: wavelength-phase velocity and frequency-phase velocity for plane Rayleigh waves and the 'simulated' axisymmetric dispersion curve (Figs (a) and (b)), modal displacements (Figs (c)), and the normalized rate of energy transmission for the first three modes (Figs (e), (d) and

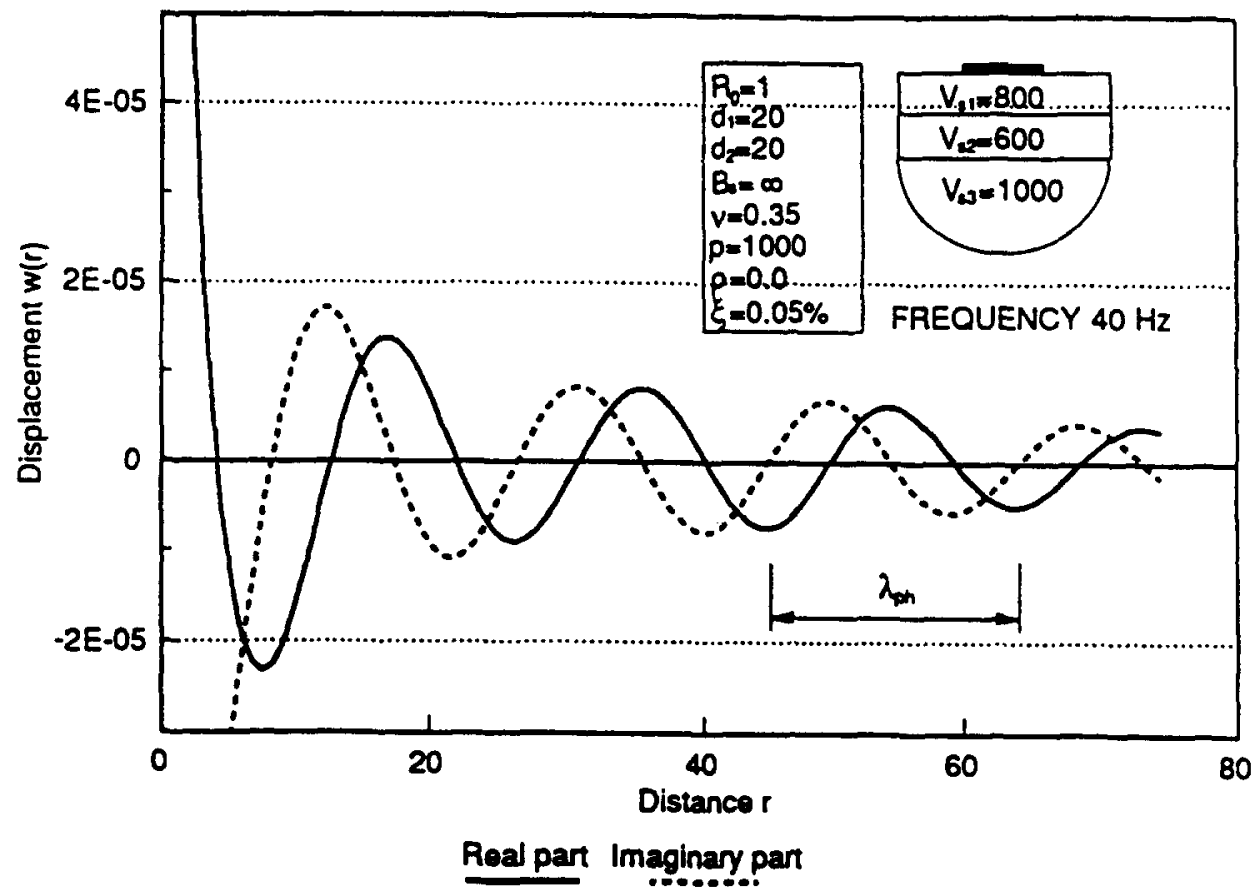

Fig. 6. Surface vertical displacements in the spatial domain and evaluation of the wavelength of the 'simulated' dispersion curve.' 
CASE 1

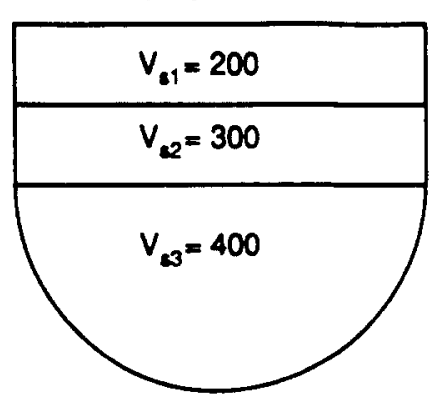

CASE 3

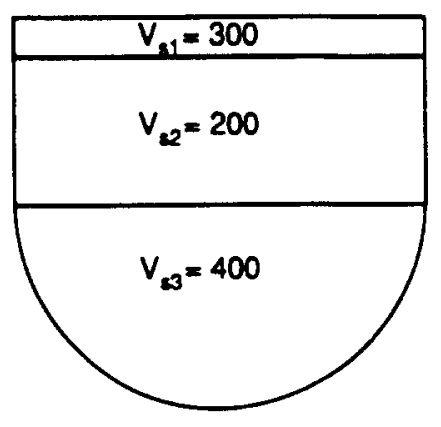

CASE 2
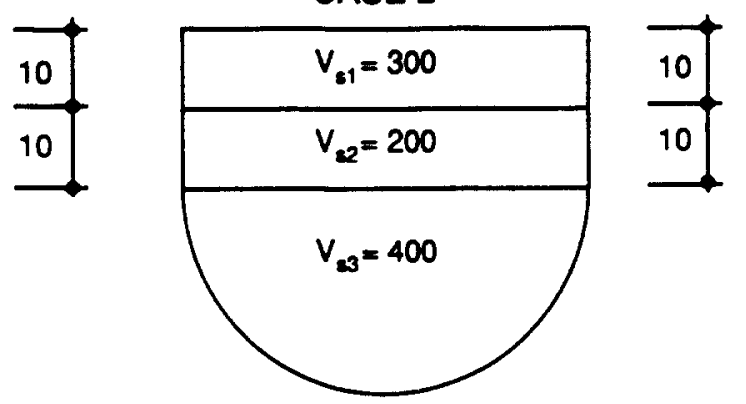

CASE 4

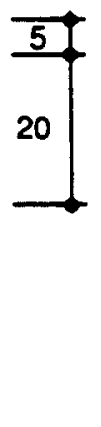

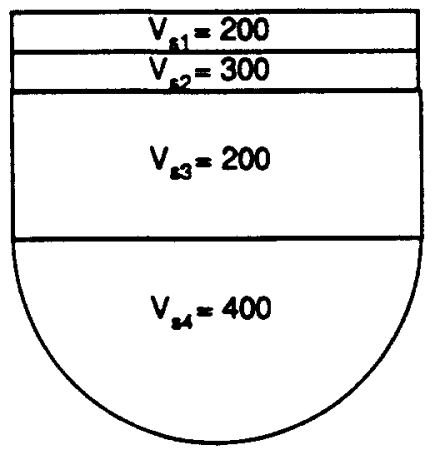

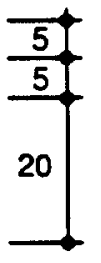

Fig. 7. Analyzed soil profiles.

(f)). All the variables and results do not have defined units, even though implementation of SI units would provide realistic properties of soil profiles.

The dispersion curves of case 1 profile follow a well known pattern. The first mode, Fig. 8(b), starts at zero frequency with the Rayleigh wave velocity of the halfspace and approaches the Rayleigh wave velocity of the surface layer as frequency increases. Higher modes start at their cut-off frequencies with the shear wave velocity of the half-space and approach the shear wave velocity of the surface layer. The dispersion curves are well separated and the 'simulated' curve follows the first Rayleigh mode curve very well. This is an excellent agreement with the modal displacements, Fig. 8(c), which indicate a dominant contribution of the first mode. Figures 8(d), (e), (f) for normalized rate of energy transmission show that the dominant portion of energy is transmitted by the surface layer for all three modes. Only in the narrow range of low frequencies $(<5 \mathrm{~Hz})$ the first mode wave penetrates deep into the half-space and causes a dominant transmission through the half-space.

Dispersion curves for case 2 profile, Fig. 9, contain localized approaches of pairs of dispersion curves. The 'simulated' dispersion curve in the wavelength-phase velocity relationship indicates a transition from the first towards higher modes, as the wavelength becomes shorter than the combined thickness of the layers above the half-space, 20 in this case. In the frequency-phase velocity relationship it follows the first mode curve up to about $15 \mathrm{~Hz}$. At $15 \mathrm{~Hz}$ it moves towards the second mode, at $25 \mathrm{~Hz}$ towards the third mode, and at about
$38 \mathrm{~Hz}$ towards the fourth mode. Those transition points are very well matched with transition points of modal displacements. The 'simulated' curve approaches the Rayleigh wave velocity of the surface layer as frequency increases. It should be mentioned that frequencies 15, 25 and $35 \mathrm{~Hz}$ perfectly match natural frequencies of the second, the third and the fourth mode of vertical oscillations of a layer of the thickness of the combined two layers and the shear wave velocity of the lower layer over a rigid half-space. Another interesting observation is that the dispersion curves of all the modes approach the shear wave velocity of the second layer, 200, as frequency increases. This may not be evident to the reader from Fig. 9(b), but if curves were continued to higher frequencies this is confirmed. Higher frequencies were not plotted here for conservation of space. This observation is in good agreement with plots of energy transmission. All the modes indicate transmission of energy completely within the second layer as frequency increases. Also, the transitions of energy transmission from the first to the second layer match very well the transitions between the modes, i.e. at about 15,25 and $38 \mathrm{~Hz}$.

The dispersion curves, modal displacements and rates of energy transmission for case 3, Fig. 10, do not differ significantly from those for case 2 . The transition points correspond well again to the natural frequencies of vertical oscillations of the combined layers. Also, a particular mode contributes significantly as long as it has a significant energy transmission within the surface layer. It should be noted that in this case the thickness of the surface layer is four times that of the second layer. This 


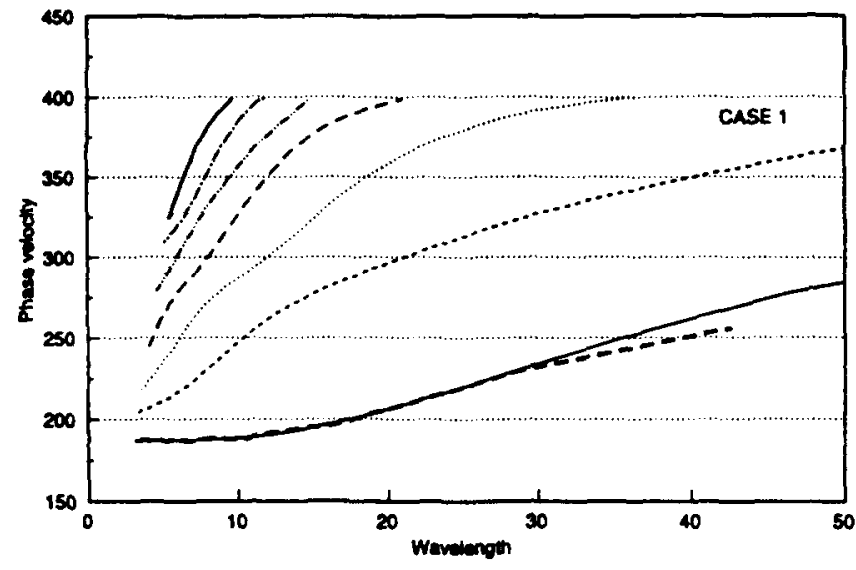

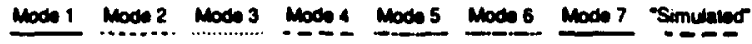

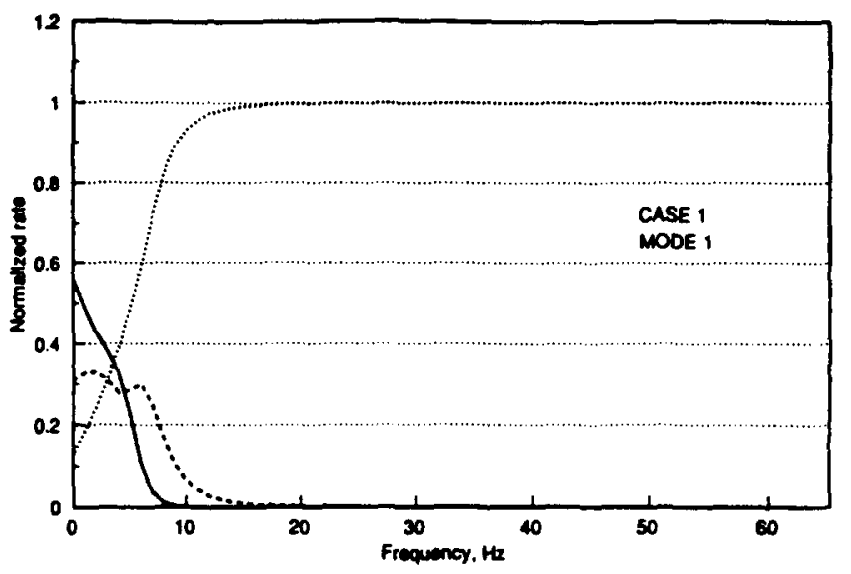

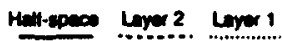

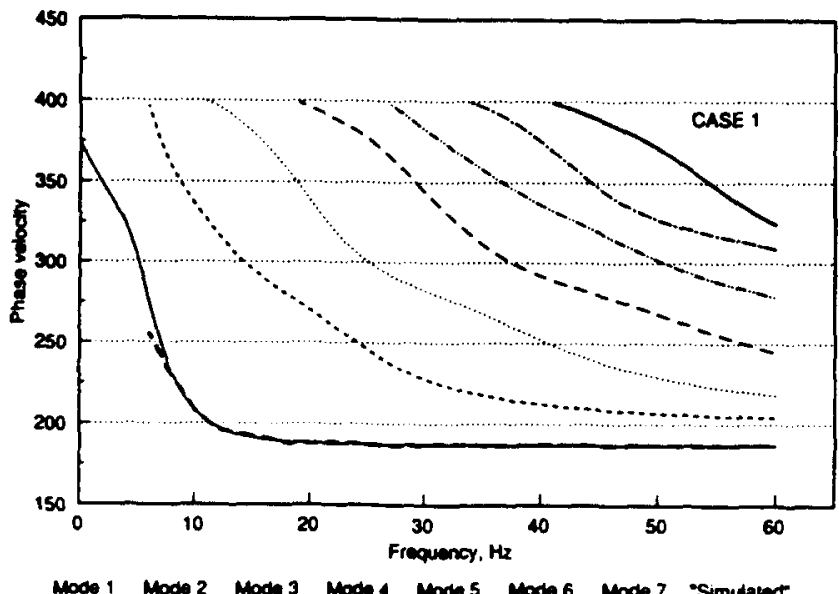

Mode 1 Mode 2 Mode 3 Modes Modes Mode 6 Mode 7 Simulaiod

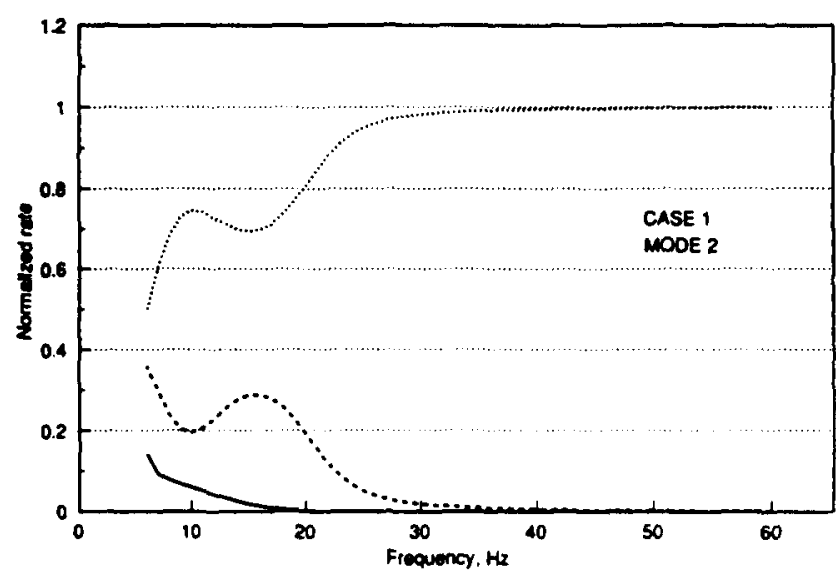

Hell-epece Leyer 2 Leyer I

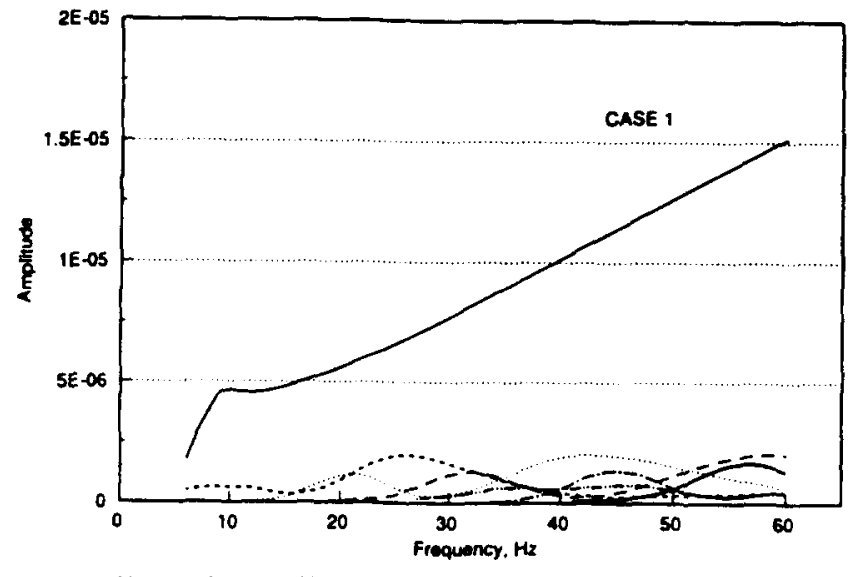

Mode 1 Mode 2 Mode 3 Modes Mode 5 Mode 6 Mode 7

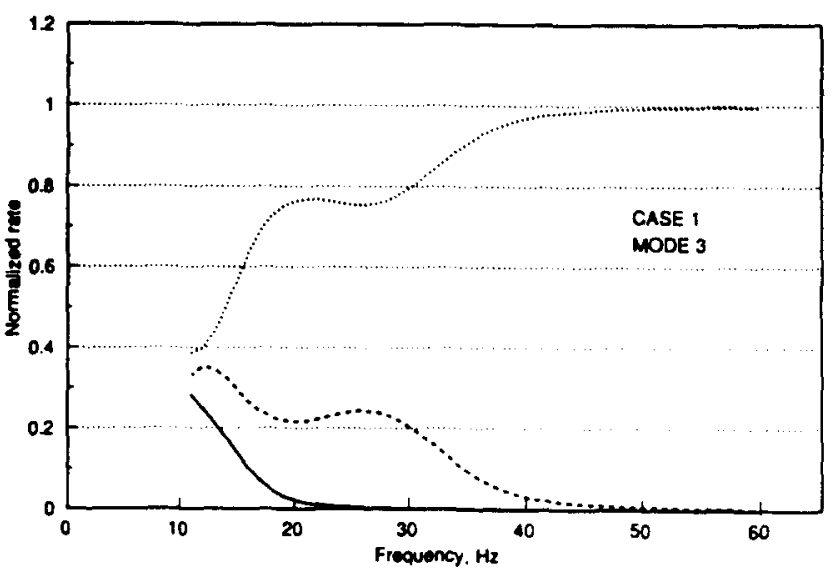

Hallepece Layer 2 Layer 1

Fig. 8. Case 1 dispersion curves [(a) and (b)], modal displacements [(c)] and the normalized rate of energy transmission [(d), (e) and (f)]. 


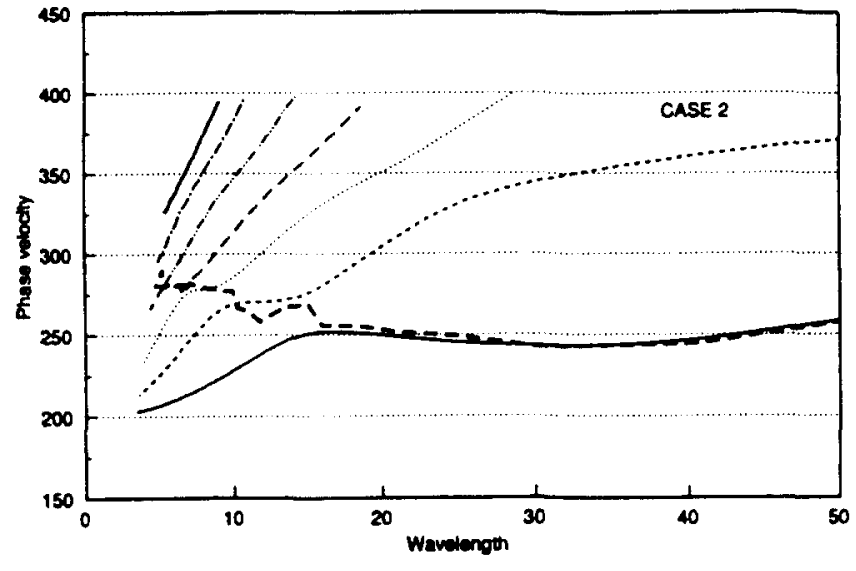

Mode 1 Mode 2 mode 3 Modes Mode 5 Mode 6 Mode 7 Simulator

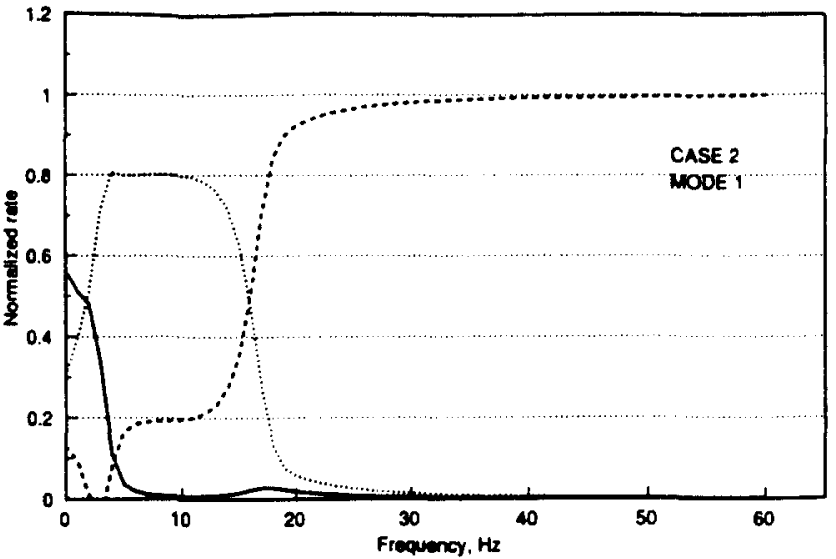

Hatf-epece Leyer Leyer 1

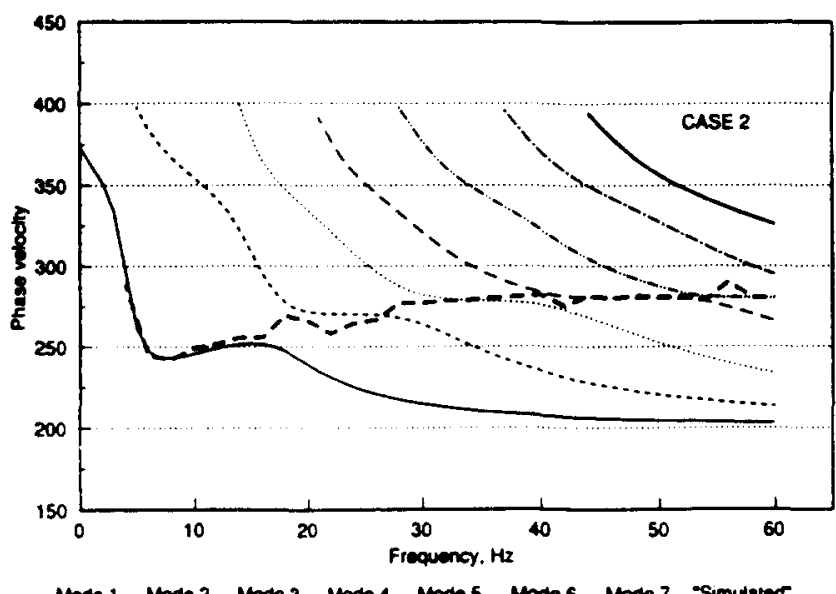

Mode 1 Mode 2 Mode 3 Modes Mode 5 Mode 6 Mode 7 Simulatiog

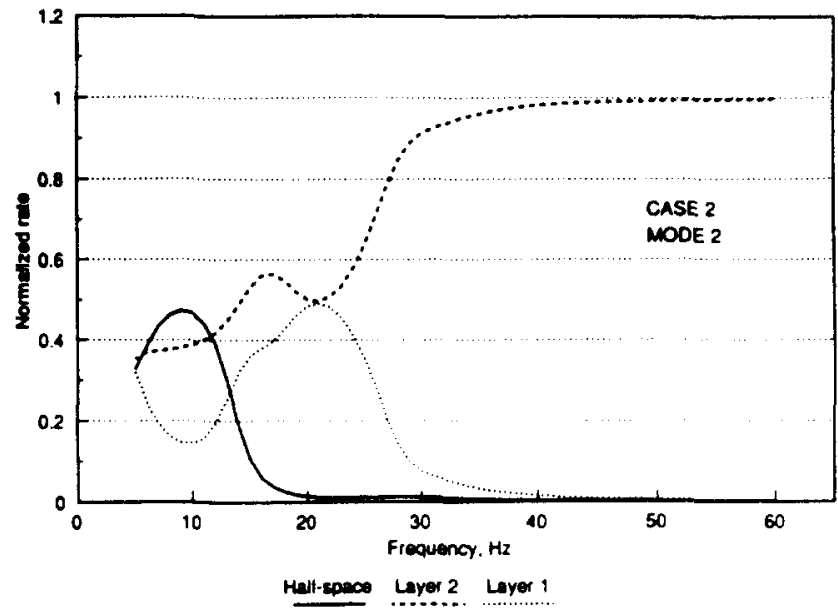

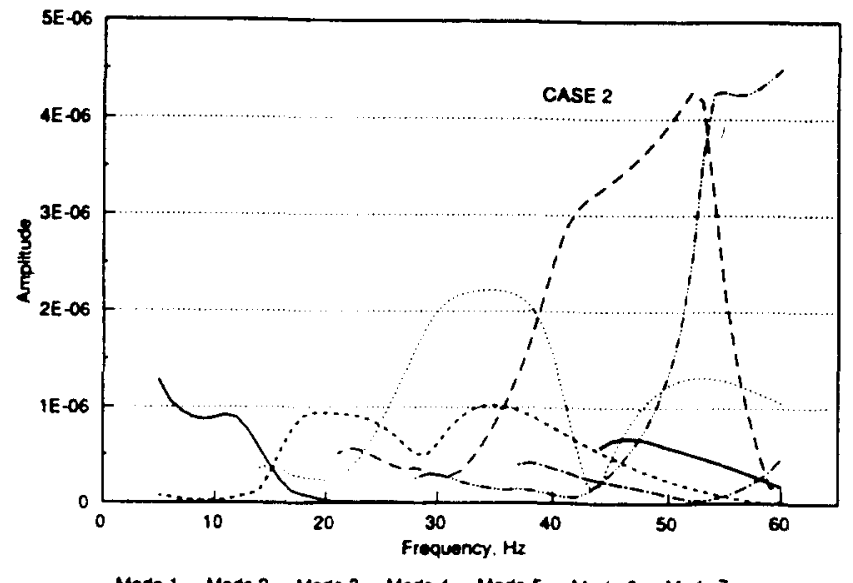

Mode 1 Mode 2 mode 3 Mode 4 Mode 5 mode 6 Mode 7

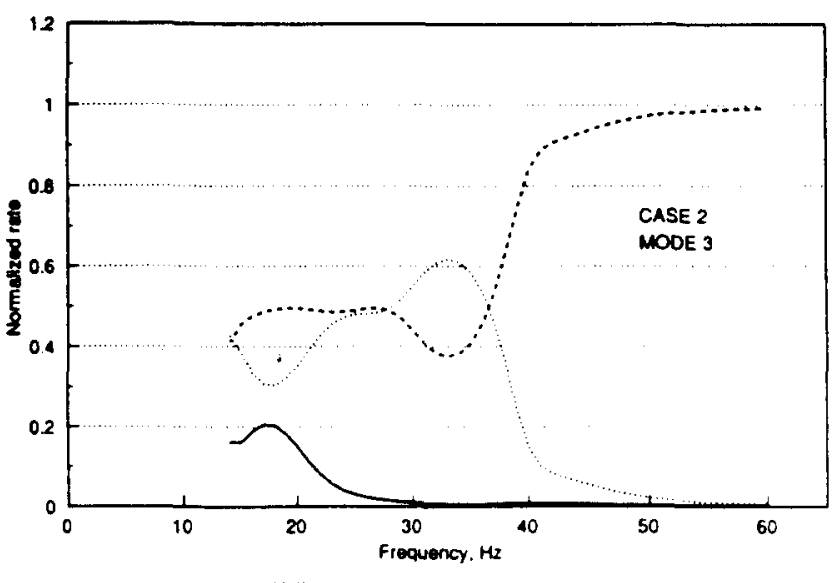

Hall-speos Layer 2 Loyer?

Fig. 9. Case 2 dispersion curves [(a) and (b)], modal displacements [(c)] and the normalized rate of energy transmission [(d), (e) and (f)]. 


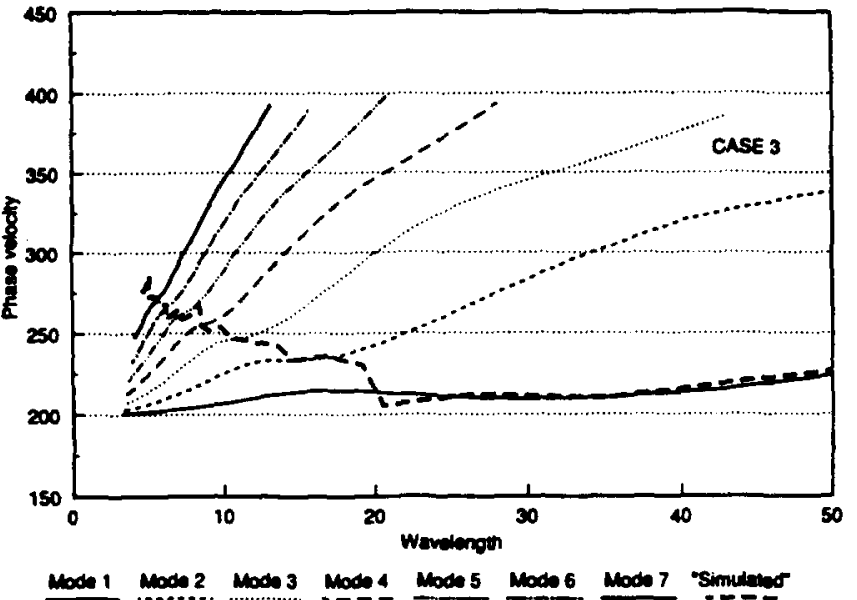

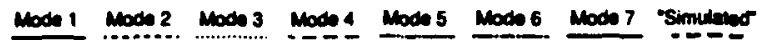

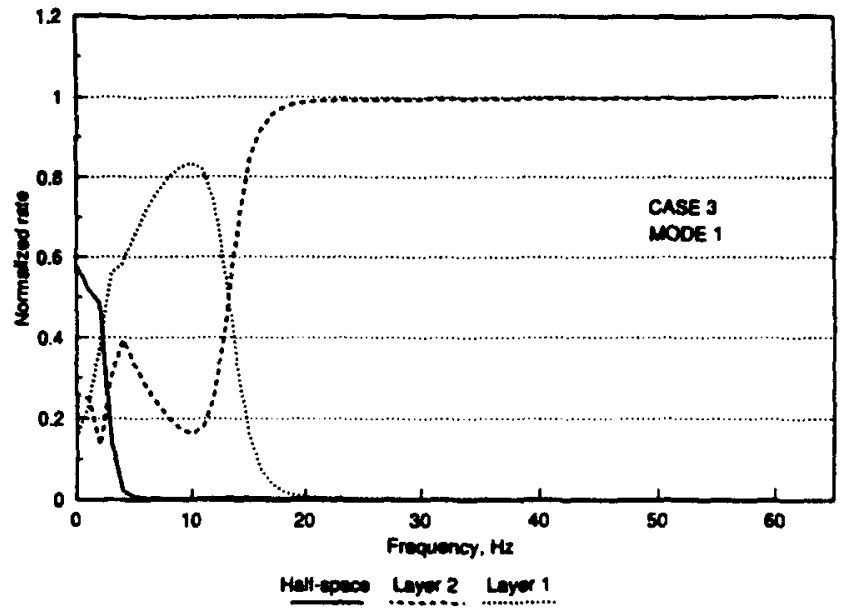

Hettapes Lyer2. Leyer. 1

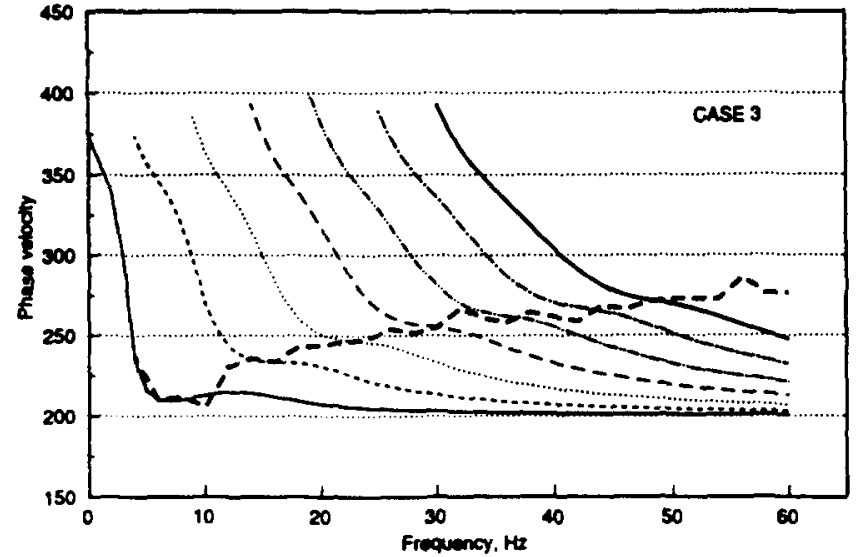

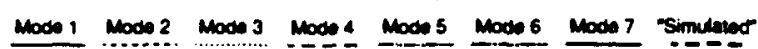

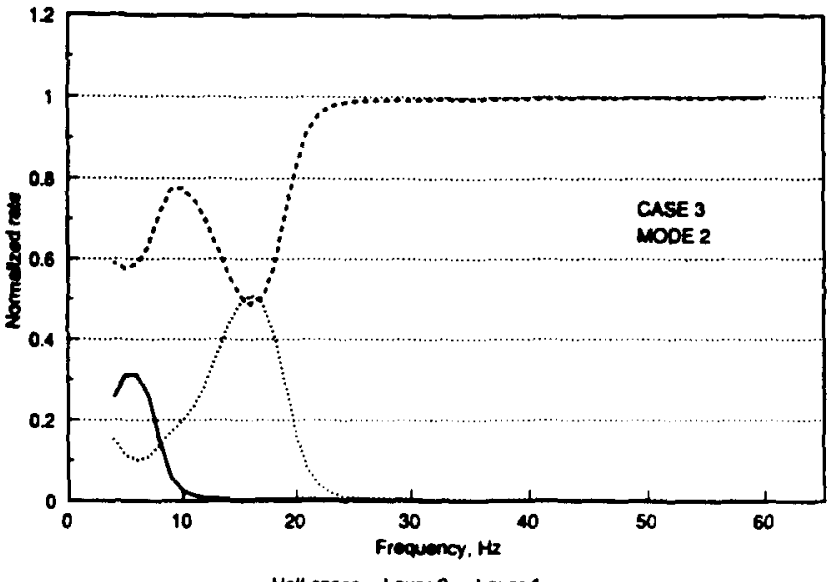

Haltepace Leyer 2 Layer 1

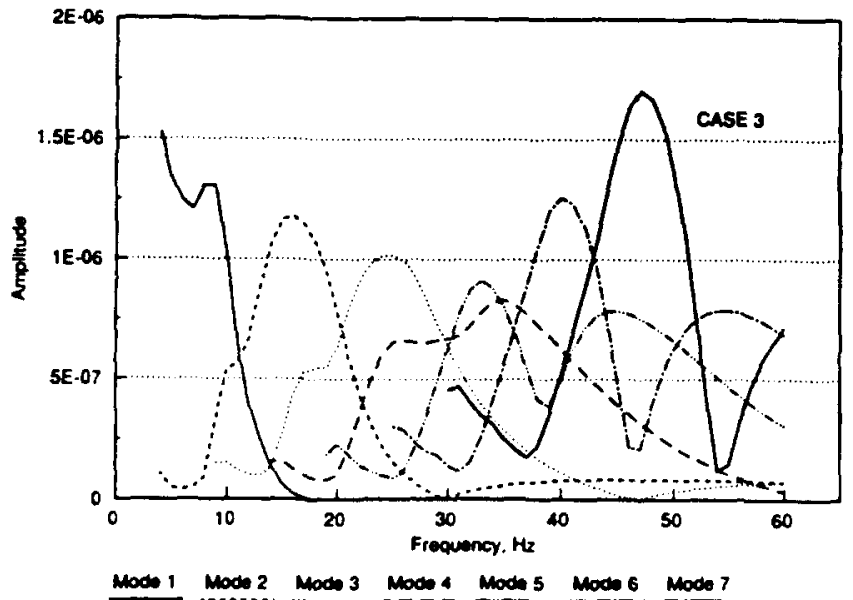

Mode 1 Mode 2 Mode 3 Modes Mode 5 Mode 6 Mode 7

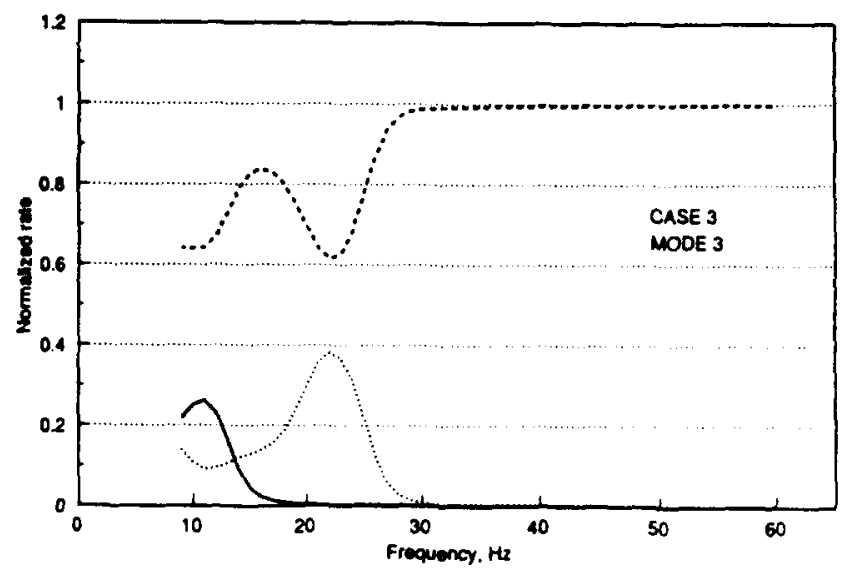

Halt-epece Layer 2 Lever I

Fig. 10. Case 3 dispersion curves [(a) and (b)], modal displacements [(c)] and the normalized rate of energy transmission [(d), (e) and (f)]. 

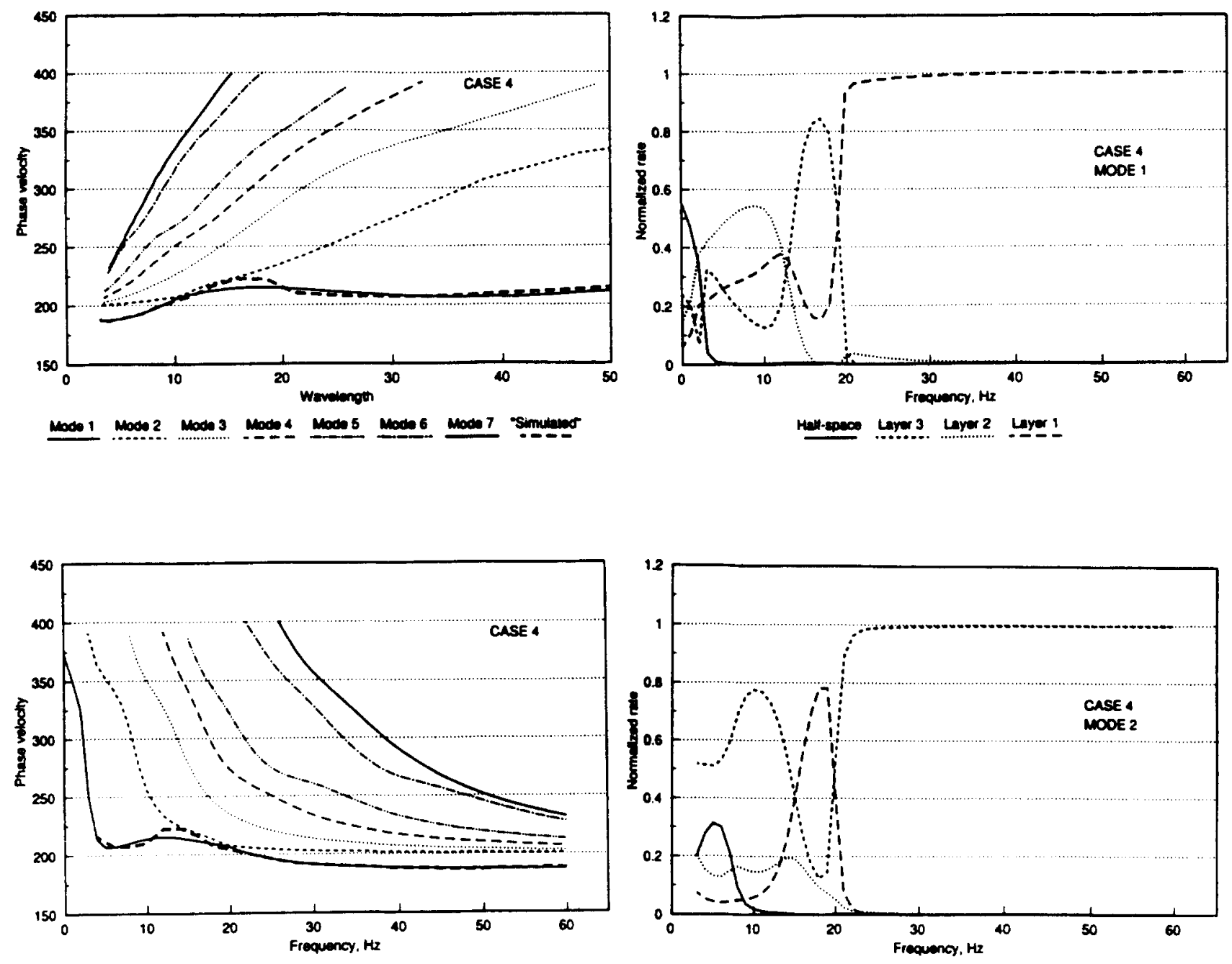

Mode 1 Mode 2 Modes Mode 4 Moos 5 Mode 6 Mode 7 Simulater

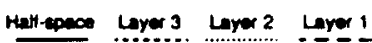

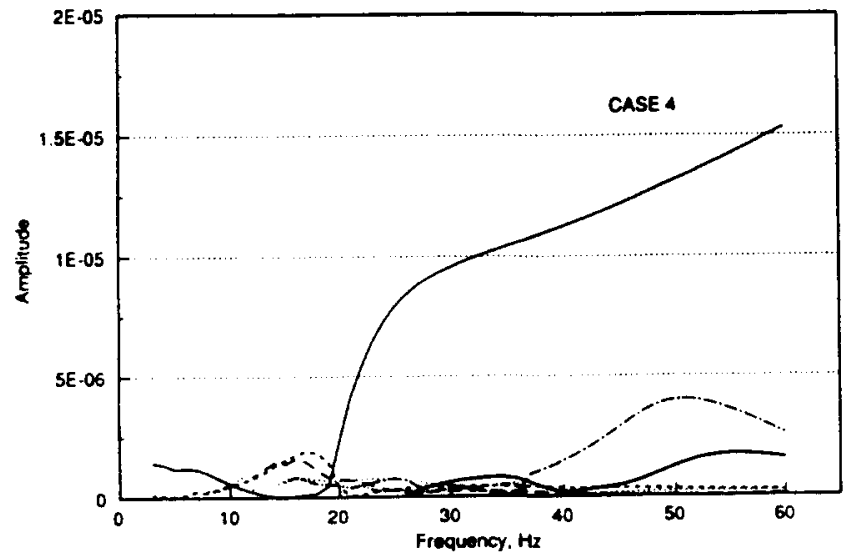

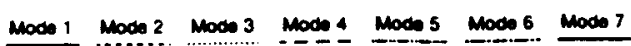

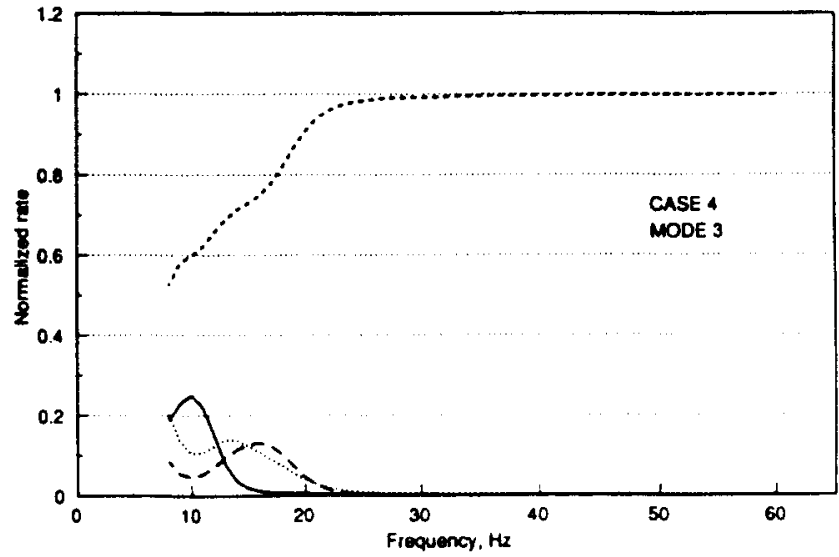

Hall-epece Leyer 3 Lever? Layer 1

Fig. 11. Case 4 dispersion curves [(a) and (b)], modal displacements [(c)] and the normalized rate of energy transmission [(d), (e) and (f)]. 

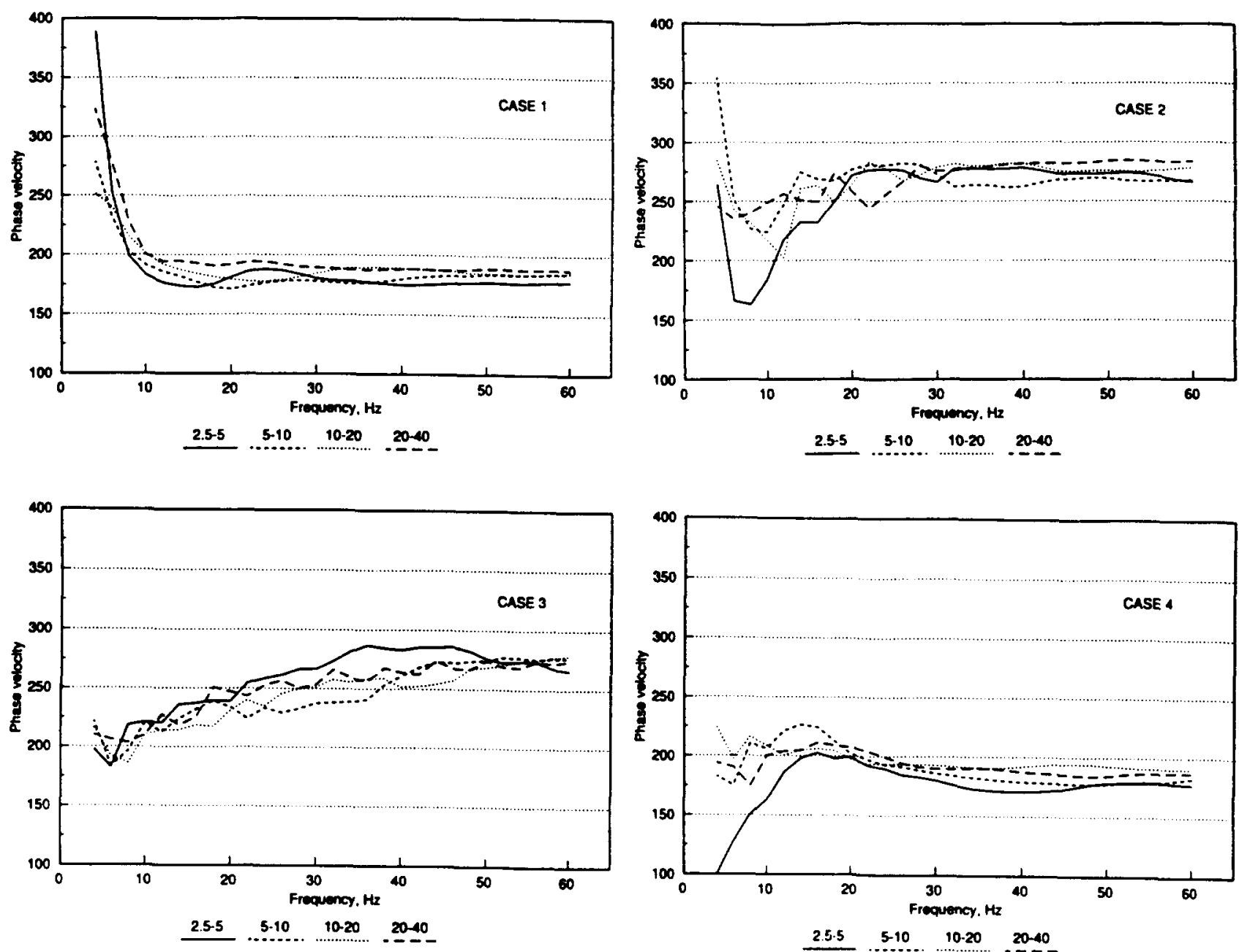

Fig. 12. Unfiltered dispersion curves for four source to near receiver and receive spacings.

is a primary reason for a higher ratio of transmission between the second and the first layer, than in case 2 .

The dispersion curves for case 4, Fig. 11, show similar behavior to those for case 1 . Higher mode curves are not approaching the shear wave velocity of the surface layer, but of the third layer as frequency increases. This is confirmed by the plots of the normalized rate of energy transmission. Dispersion curves for the first two modes which are characterized by a localized approach between 10 and $20 \mathrm{~Hz}$. In the same frequency range the 'simulated' curve converges towards the second mode curve. Significant influence of the second and the third Rayleigh mode is attributed to natural vertical oscillations of the combined layered system and the surface layer in that frequency range. The natural frequency of the second mode of vertical oscillations, of a layer of the thickness of the combined three layers over a rigid base, is about 10. The natural frequency of the first mode of vertical oscillations of the surface layer on the rigid base, is about $20 \mathrm{~Hz}$. In this case, because of a flexible base, it is somewhat lower. The plot of energy transmission of the second mode supports well this observation.

\section{(b) Source to near receiver and receiver spacing}

This section presents results of the study on influences of soil stratification on the results obtained from the SASW test. It examines particularly effects of: (1) source to near receiver distance; (2) receiver spacing; and (3) filtering criteria in averaging processes of generation of the experimental dispersion curve for the presented cases of soil stratification. Figure 12 represents the dispersion curves obtained for four source to near receiver distances and receiver spacings if no filtering was applied. The first number in the legend represents the source to near receiver distance, while the second represents the source to far receiver distance. The legend indicates that in all the cases the source to near receiver distance $S$ was equal to the receiver spacing $X$. The figure shows that the source to near receiver distance had the least affect on the scattering of dispersion curves in case 1 , and the most in case 2. Case 1 exhibits significant variations in phase velocities only in a lower frequency range, approximately $0-10 \mathrm{~Hz}$, or for wavelengths larger than about 20 . Case 2 exhibits variations for frequencies less than about $27 \mathrm{~Hz}$, 

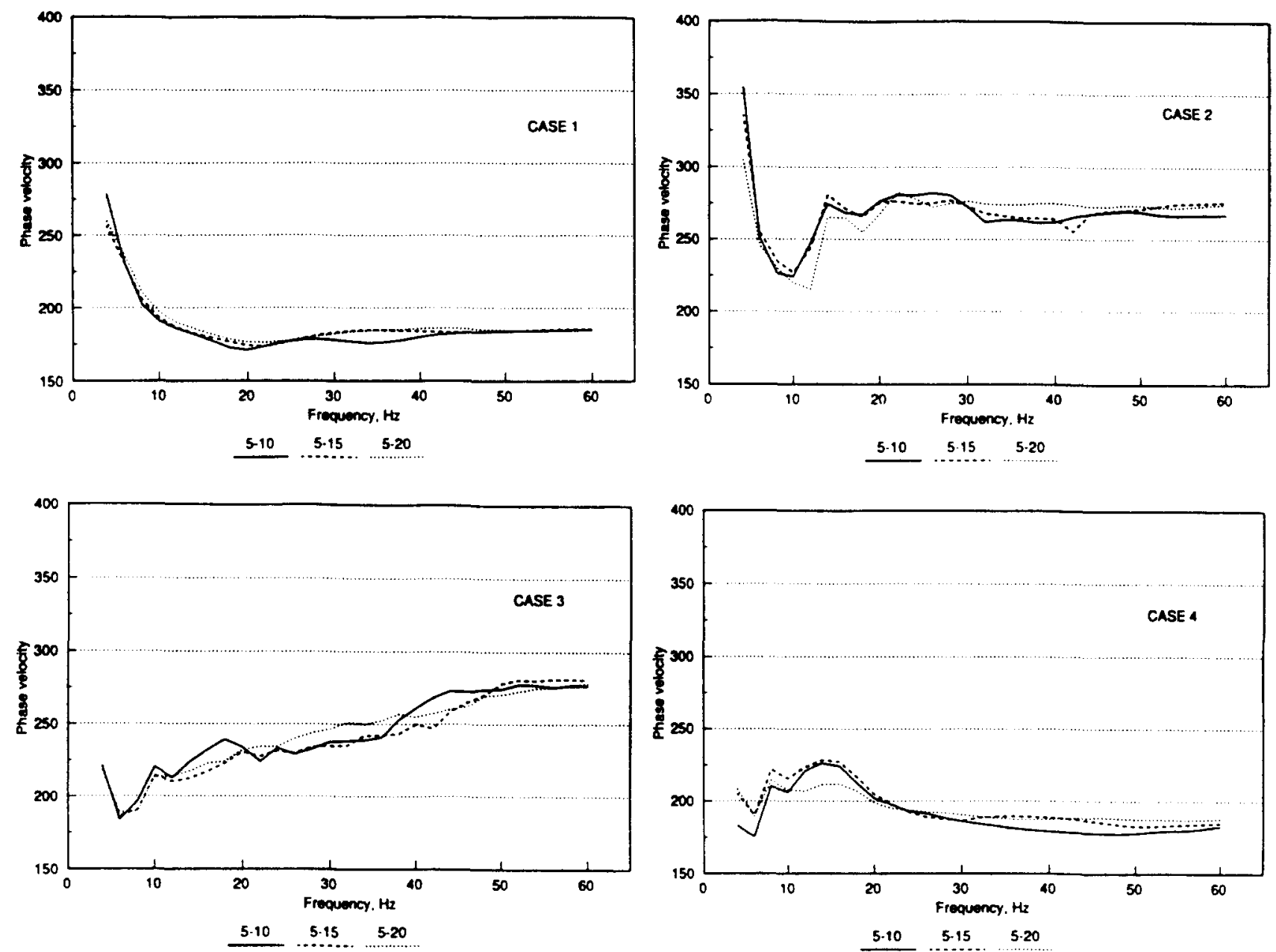

Fig. 13. Unfiltered dispersion curves for the source to near receiver spacing equal to 5 and variable receiver spacing.

or wavelengths again larger than about 10 . Case 3 dispersion curves vary significantly for frequencies less than about $50 \mathrm{~Hz}$, or wavelengths larger than 5 . Finally, case 4 dispersion curves vary below $20 \mathrm{~Hz}$, or for wavelengths less than 10. Results of cases 2,3 , and 4 lead to a conclusion that variations occur when the wavelength becomes larger than the combined thickness of layers which can be said to represent a regular soil profile.

Figure 13 illustrates influence of the receiver spacing on the results from SASW test for various soil stratifications. The receiver spacing indicates very low effect in cases 1,3 and 4 . Differences in results are generally below $10 \%$. Case 2 has substantially higher differences in phase velocities of dispersion curves, exceeding at certain points $15 \%$. The observations and conclusions stated in the previous paragraph, regarding the limiting values of wavelengths for which the stronger differences occur, are valid here too.

Figures 14 and 15 illustrate full simulation of the SASW test. Dispersion curves in Fig. 14 for four spacings from Fig. 12 have been filtered according to Heisey's criteria and averaged as described by Nazarian. "In addition the 'simulated' dispersion curve, which is considered to represent the best estimate of the average dispersion curve, has been plotted. The figure shows a good agreement of the average and the 'simulated' curve in case 1 . These two curves have significant differences, exceeding $15 \%$ in the low frequency range, in cases 2,3 and 4. Dispersion curves for particular receiver spacings can differ significantly from the average dispersion curve. This can be attributed to two causes. The first is that Heisey's criteria accepts wavelengths of waves too close to the source, where the wave is still in a process of formation. The second cause is possible interference of several Rayleigh modes and body waves, as described by Gucunski \& Woods. ${ }^{2,3}$ This interference is more pronounced closer to the source.

Several other filtering criteria have been examined. Figure 15 represents the same set of curves in Fig. 14 but filtered by the criteria

$$
\lambda_{\mathrm{ph}}<X<4 \lambda_{\mathrm{ph}}
$$

In all four cases there is an excellent agreement between the average and the 'simulated' dispersion curves, except 

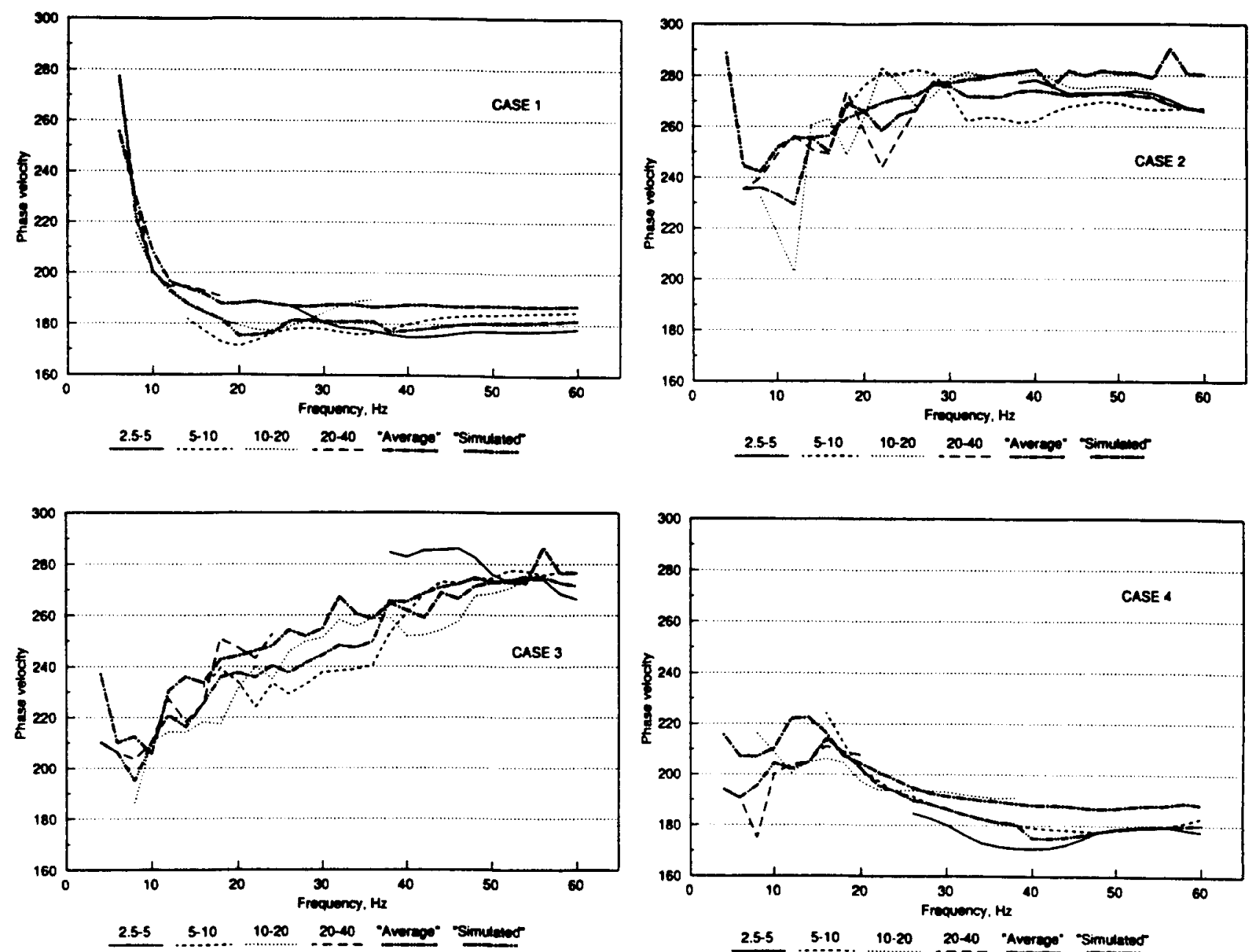

Fig. 14. Dispersion curves filtered by Heisey's criteria, the average and the 'simulated' dispersion curves.

in narrow frequency ranges of cases 2,3 and 4 . It should be noted that implementation of the lower boundary of this criteria in practice, instead of Heisey's, would have a consequence that the obtained profile would be approximately three times shallower. That would increase the need for a powerful impact source even more whenever deep soil measurements are performed. The other potential problem might rise in an effort to satisfy the upper boundary of the criteria. Field testing might show that a signal, attenuated at that distance from the source, might be contaminated too much by ambient noise. This problem in the field would be automatically corrected by the coherence function.

\section{SUMMARY, CONCLUSIONS AND RECOMMENDATIONS}

The paper provides a brief overview of the SpectralAnalysis-of-Surface-Waves (SASW) method and a description of its numerical simulation. The numerical simulation was used to evaluate potential influences of the test setup on the results for various soil stratification conditions. The following are conclusions of the study:

(1) Wave field generated by a vertical circular surface loading in soil systems of regular stratification, i.e. when the shear wave velocity increases with depth, is dominated by the first Rayleigh mode. Because of that the obtained dispersion curves are affected only by the source to near receiver spacing. Heisey's filtering criteria provides sufficiently accurate results, except in the lowest frequency range, in which the dispersion curve for the largest receiver spacing is not averaged with the others.

(2) Higher Rayleigh modes can play a significant role in wave propagation in soil systems of irregular stratification. The resulting waves often represent superposition of two or more modes of Rayleigh waves and body waves. Therefore, the obtained dispersion curve is strongly influenced by the test setup. Dispersion curves filtered by Heisey's criteria can differ significantly from the true, far field dispersion curve. Differences are especially 

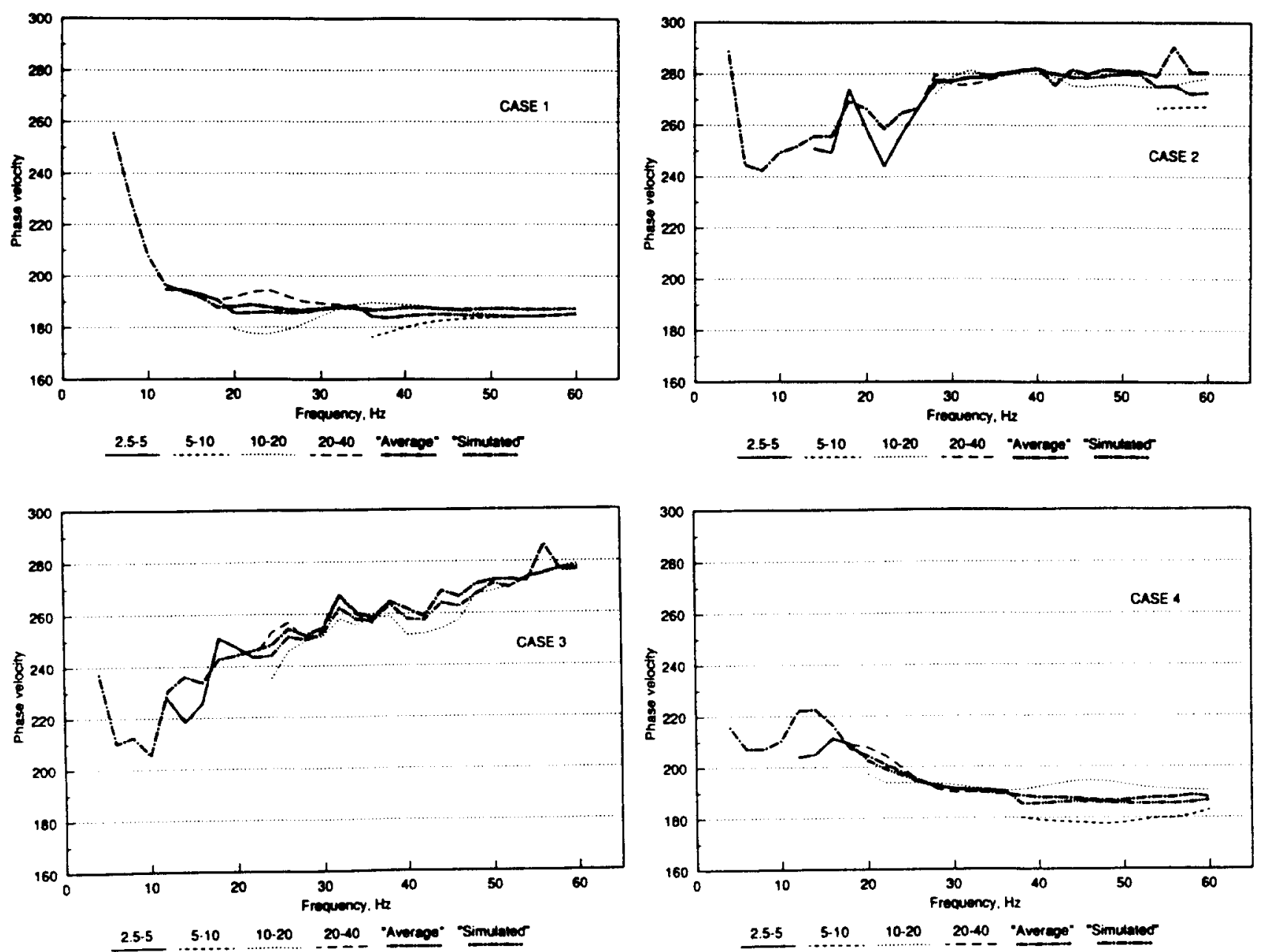

Fig. 15. Dispersion curves filtered by the criteria from eqn (7), the average and the 'simulated' dispersion curves.

pronounced in cases of soil systems with a hard surface layer and in a low frequency range.

(3) The irregular soil profile behaves as the regular one until the wavelength of the Rayleigh is less than approximately the thickness of the top portion of the system which can be described as a regular profile.

(4) Errors in the definition of the field dispersion curve for the irregular soil systems can be significantly reduced by applying the filtering criteria given by eqn (7). Implementation of that criteria would also improve accuracy of results for the regular soil systems.

The analysis presented did not assume presence of any obstacles commonly encountered in SASW testing, like: ambient noise; presence of other sources of vibrations; material and geometrical inhomogeneity of a soil system; limited characteristics of the equipment. Therefore, it is recommended that a series of field tests is performed which would eventually lead to accommodation of the previously suggested filtering criteria for SASW testing.

\section{REFERENCES}

1. Gucunski, N. Generation of low frequency Rayleigh waves for the Spectral-Analysis-of-Surface-Waves Method, Ph.D Dissertation, Department of Civil Engineering, The University of Michigan, Ann Arbor, pp. 313, 1991.

2. Gucunski, N. \& Woods, R.D. Use of Rayleigh modes in interpretation of SASW test, Proceedings of the Second International Conference on Recent Advances in Geotechnical Earthquake Engineering in Soil Dynamics, Vol. II, St. Louis, Missouri, March 11-15, pp. 1399-1408, 1991.

3. Gucunski, N. \& Woods, R.D. Inversion of Rayleigh Wave Dispersion Curve for SASW Test, Proceedings of the 5th International Conference on Soil Dynamics and Earthquake Engineering, Karlsruhe, Germany, Sep. 23-26, pp. 127-138, 1991.

4. Gucunski, N. \& Woods, R.D. Instrumentation for SASW testing, Recent Advances in Instrumentation, Data Acquisition, and Testing in Soil Dynamics, Geotechnical Special Publication No. 29, ASCE, pp. 1-16, 1991.

5. Heisey, J.S., Stokoe, K.H.II, Hudson, W.R. \& Meyer, A.H. Determination of in situ shear wave velocities from Spectral Analysis of Surface Waves, Research Report No. 256-2, Center for Transportation Research, The University of Texas at Austin, December, 277 pp., 1982. 
6. Hiltunen, D.R. Experimental evaluation of variables affecting the testing of pavements by the Spectral-Analysisof-Surface-Waves method, Ph.D. Dissertation, Civil Engineering Department, The University of Michigan, 303 pp., 1988.

7. Kausel, E. (1981), An Explicit Solution for the Green Functions for Dynamic Loads in Layered Media, M.I.T. Research Report R 81-13, Order No. 699, Dept. of Civil Engineering, M.I.T., Cambridge, Mass.

8. Kausel, E. \& Roesset, J.m. Stiffness Matrices for layered soils, Bulletin of Seismological Society of America, 1981, 71(6), 1743-1761.

9. Kausel, E. \& Peek, R. Dynamic loads in the interior of a layered stratum: an explicit solution, Bulletin of Seismological Society of America, 1982, 72(5), 1459-1481.

10. Lysmer, J. Vertical motion of rigid footings, U.S. Army Engineers Waterways Experiment Station, Report No. 3115, Vicksburg, Mississippi, 137 pp., 1965.
11. Nazarian, S., Stokoe, K.H.II \& Hudson, W.R. Use of spectral analysis of surface waves method for determination of moduli and thicknesses of pavement systems, Transportation Research Record, No. 930, pp. 38-45, 1983.

12. Nazarian, S. In situ determination of elastic moduli of soil deposits and pavement systems by Spectral-Analysis-ofSurface-Waves method, Ph.D. Dissertation, Civil Engineering Department, The University of Texas at Austin, 1984.

13. Roesset, J.M., Chang, D.-W., Stokoe, K.H. II \& Aouad, M. Modulus and thickness of the pavement surface layer from SASW tests, Transportation Research Record, No. 1260, pp. 53-63, 1989.

14. Sanchez-Salinero, I., Roesset, J.M., Shao, K.-Y., Stokoe, K.H.II \& Rix, G.J. Analytical evaluation of variables affecting surface wave testing of pavements, Transpor- 